EDITORIAL

\title{
50 years: Beiträge zur Algebra und Geometrie
}

\author{
Horst Martini ${ }^{1}$
}

Published online: 15 March 2021

(c) The Managing Editors 2021

This is the second issue of our anniversary volume on the occasion of the 50th birthday of the journal "Beiträge zur Algebra und Geometrie" (BZAG) in 2021. The three managing editors decided to present the broad mathematical spectrum of the journal by publishing appropriately selected papers written by members of its Editorial Board. These articles will be compiled in the first two issues of the year 2021. Before presenting the articles of the correspondingly second issue, we first give here a summary of the history of the journal.

The journal BZAG was founded in 1971 on the occasion of the 65th birthday of Ott-Heinrich Keller, who during the initial period of BZAG also worked as managing editor for this journal. O.-H. Keller had a permanent position as professor at the Martin-Luther-University Halle-Wittenberg and good international reputation in his subject of research. He was born in 1906, in Frankfurt am Main, and studied at universities in Vienna, Berlin, Göttingen, and Frankfurt; in Frankfurt Max Dehn was his PhD supervisor, and later he habilitated as assistant of Georg Hamel (TH Berlin). After this he was Professor in Münster and in Dresden, until he finally got in 1952 his professorship in Halle (previously held by Heinrich Wilhelm Ewald Jung). In 1961, O.-H. Keller became president of the German Mathematicians Association (DMV); he was the last president before this association was separated into the (West German) DMV and the (East German) Mathematical Society of GDR. He retired in 1971. His main fields of research were geometry, topology, algebraic geometry, and also some number theory. In particular, he posed in 1930 the famous Keller conjecture on tilings of the $n$-dimensional Euclidean space by identical cubes. It says that in any such tiling there are two cubes that meet face to face. As not uncommon in discrete geometry, it is known to be true in spaces of relatively low dimension, and then false in higher dimensions. Later O.-H. Keller worked, for example, on Cremona transforms and singularities of algebraic curves, on ideal theory, and on the topological structure of algebraic surfaces. He wrote a book on algebraic geometry and a booklet (as part of a comprehensive encyclopedic work) on the geometry of numbers.

Horst Martini

horst.martini@mathematik.tu-chemnitz.de

1 University of Technology Chemnitz, Chemnitz, Germany 
The idea of such a journal started in principle in 1966, with a meeting on the occasion of the 60th birthday of O.-H. Keller. His colleagues, in particular Otto Krötenheerdt, started to collect written versions of scientific contributions presented at this and further meetings. These contributions at first were published in the university journal of Halle. Because these meetings were organized regularly in the years to follow, the need for a regular publication of the corresponding results became evident, and this lead to the foundation of BZAG in 1971. The book company publishing it was "VEB Deutscher Verlag der Wissenschaften". From the very beginning, the scope of the new journal was inspired by the research of O.-H. Keller. But this spectrum was also largely extended, e.g. by fields like differential geometry, group theory, and many others. There is no question that today the journal publishes high-impact research articles in various directions of algebra, geometry, and algebraic geometry.

In East Germany there were only restricted opportunities to publish related articles in Western high-quality journals. To mention this is essential, since for most scientists from East Germany it was (in principle possible, but) difficult to publish in the so-called Western world, by several reasons. E.g., for most scientists in East Germany a normal, purely scientific correspondence with colleagues in the West was officially not allowed. Thus, scientists from the East had, in general, international contacts only to "socialist brother countries".

As one consequence of this scientific isolation, most scientists could or did not submit research articles for publication in high-level journals. They even did not know all of these journals. To compensate such problems, they had to choose journals from other socialist countries. In some cases this was a successful method; for example, specialists in discrete and convex geometry tried to publish in Hungarian journals (which was, due to the leading role of Hungary in this subject, a good option). In other research areas, this was not so easy. As a consequence, the journal BZAG played an important role until the turn in 1989 or more precisely until 1993 (see below). It was also an important part for the acquisition of other journals by exchange agreements! In spite of this, the journal got less and less official support, finally also visible from its low printing quality and rather simple layout.

Returning to the history of the journal BZAG, let us have a short look at the chronological list of main editors of it. The first issue (1971) was dedicated to OttHeinrich Keller on the occasion of his 65 th birthday, and its contents were compiled by the editors Manfred Herrmann, Andor Kertész, and Otto Krötenheerdt. In the second issue, this group of editors was completed by Ott-Heinrich Keller himself, and in 1976 Ludwig Stammler came along. Since A. Kertész passed away in 1974, Eleggius Tamos Schmidt joined the group since 1975. With Volume 13 (1983) M. Herrmann and with Volume 15 (1985) E. T. Schmidt left, such that since 1984 the following mathematicians were editors: Hans-Jürgen Hoehnke, O.-H. Keller, O. Krötenheerdt, L. Stammler, and Wolfgang Vogel. In 1990, O.-H. Keller passed away, and in Volume 32 his work was honored with a comprehensive obituary.

Shortly before the turning point in 1989, the layout and printing of the journal BZAG were at such a low level that an improvement was needed urgently. In addition, it was a big question whether it would survive this period. Since the publisher "VEB Deutscher Verlag der Wissenschaften" finally was liquidated, a 
new business model for publishing the journal was requested. Even worse, due to this liquidation the complete list of subscribers got lost. On request of O. Krötenheerdt, Bernd Wegner started to develop such a model using his experience and connections, coming from his work as editor-in-chief of Zentralblatt MATH. He finally could guarantee the survival of the BZAG. Only some particular aspects should be mentioned here. With the help of many colleagues all over the world, B. Wegner succeeded to recover the lost subscribers, which was vital for the survival of the journal! Two other important activities were the extension of the Editorial Board by several experts of high international reputation, and the agreement with Norbert Heldermann to include the journal BZAG into his publishing program, with a great economic involvement on the part of the publisher. In addition to this, several special activities of new editors and of colleagues from Halle helped to survive a tough transition period. For example, editors did the advertising themselves (e.g., at conferences), and colleagues from Halle (like Mrs. Buchsteiner-Kiessling) created the TeX-encoding for printing the journal and posting its electronic version. So the journal BZAG had a really "new start" as Heldermann journal in 1993; as managing editors thenceforth Bernd Wegner, Jürgen Stückrad, Otto Krötenheerdt, and Gerhard Michler started to work. Slowly the journal established itself more and more, and step by step the success became visible. E.g., with the partnership of the SUB Göttingen, retro-digitizing the printed-only back volumes, BZAG was one of the first mathematical journals with a complete digital offer. Part of this was that the journal was posted online via the ELibM in EMIS (world-wide).

A further important step was, in agreement with Norbert Heldermann, the transfer of the journal to the Springer publishing house (the April issue in 2011 was the first Springer issue). This finished a period of additional and extraordinary efforts of editors and publishers, still owed to the turning point. With the help of Springer, the journal could reach in 2017 the level of the "Emerging Sources Citation Index (ESCI)".

In terms of tradition and content, the journal again concentrated on the mathematical areas of geometry, algebra, and algebraic geometry, each represented by at least one of the main editors. Continuing this philosophy, Gernot Stroth replaced G. Michler in 1996, and 11 years later Horst Martini replaced B. Wegner. In 2017 J. Stückrad was replaced by Daniel Greb, such that today the managing editors $\mathrm{H}$. Martini, G. Stroth, and D. Greb represent the fields of geometry, algebra, and algebraic geometry, respectively. Besides these managing editors, the Editorial Board of the journal consists of more than 40 active researchers which are designated in corresponding subfields.

(Choosing as example the field of geometry, such subfields are e.g. differential geometry, discrete and convex geometry, or foundations of geometry.)

Invited by the three managing editors, in the two anniversary issues (the first two issues of 2021) many members of the Editorial Board introduce themselves to the readership with scientific contributions.

Finally 28 articles came together (among them also two from former board members, and one from the former technical editor). As usual, all these contributions were subjected to a normal peer review procedure. In the first issue, mainly 
geometric papers are collected, in the second mainly papers from algebra and algebraic geometry.

In each of the two issues the articles are given in alphabetic order regarding the names of the participating members of the Editorial Board.

In the first issue these are: V. Alexandrov, F. Buekenhout, H. Havlicek, T. Jahn, M. Joswig, W. Kühnel, P. McMullen, V. Pambuccian, C. Richter, C. Sevenheck, V. Soltan, K. J. Swanepoel, T. Theobald, L. Vrancken, J. M. Wills, and S. Wu.

In the second issue, this continues with: J. Bell, D. Craven, K. Erdmann, A. A. Ivanov, A. Küronya, C. Lehn, R. Miró-Roig, B. Mühlherr, A. Pasini, D. Patil, R. Pöschel, and U. Storch.

The managing editors wish to thank all these colleagues, and also their coauthors, for contributing to this scientifically stimulating double issue of the journal BZAG!

Publisher's Note Springer Nature remains neutral with regard to jurisdictional claims in published maps and institutional affiliations. 